\title{
Dermatology relevance to graduates from the Universidade Estadual de Campinas Medical School ${ }^{*}$
}

\author{
Ariel Falbel Lugão ${ }^{1}$ \\ Eneida Lazzarini de Castro ${ }^{2}$ \\ Paulo Eduardo Neves Ferreira Velho²
}

\author{
Tânia Alencar de Caldas ${ }^{2}$ \\ Elisabete Monteiro de Aguiar Pereira²
}

DOI: http://dx.doi.org/10.1590/abd1806-4841.20153740

\begin{abstract}
BACKGROUND: Some research indicates that physicians do not dominate the expected dermatological content for the proper exercise of the profession. This fact compromises their diagnostic and therapeutic performance, generating unnecessary costs.

Oвјестіvе: The aim of this study was to evaluate the relevance of Dermatology and the knowledge acquired in the specialty during the undergraduate course in clinical practice of graduates at the State University of Campinas Medical School (FCM/UNICAMP).

MetHOD: A questionnaire with 22 closed questions and two open ones was electronically sent to physicians who had graduated more than 10 years ago and others for less than 10 years. In the first group, physicians were trained by the same curriculum and in the second group there were subjects trained by the old and the new curriculum. RESULTS: Of the 126 respondents, $83 \%$ had completed a specialization course. Among all, $82 \%$ did not study dermatology after graduation. The majority considered that Dermatology has high relevance in clinical practice, regardless of the group. There was a statistically significant difference between non-dermatologist doctors graduated for more than 10 years and those graduated for less than 10 years regarding confidence about lesion diagnosis, diagnostic investigation and treatment of skin diseases. Physicians who have graduated for a longer time feel more insecure in relation to patients with dermatoses. Concerning contributions offered by graduation program completion they prioritized outpatient care, ability to diagnose, knowledge of pathology, research and knowledge of lesions.

CONCLUSION: This study has shown that Dermatology is relevant in medical practice and more recent graduates from the FCM/UNICAMP feel less insecure when treating a patient with dermatoses.
\end{abstract}

Keywords: Dermatology; Diagnosis; Education; Professional practice 


\section{INTRODUCTION}

The discussion of curriculum issues is rarely presented in the point of view of students and graduates. Alumni curriculum evaluation is an important tool to improve the quality of the course of medicine.

Literature considers graduates relevant actors for research on undergraduate education since their concepts promote dynamic knowledge as a result of their professional experience. ${ }^{1,2,3}$

According to Richardson et al. (1999), attitudes, interests and opinions are correlated when they concern feelings or preferences connected with the activities exerted. ${ }^{4}$ The two first cited - attitudes and interests - consist in predispositions to react in a negative or positive manner with respect to an act or fact, while opinions may be considered as specific reactions in relation to the experienced act or fact.

The foundation of the Brazilian Association of Medical Education (Associação Brasileira de Educação Médica - ABEM) on August 21, 1962 fixed the objectives for medical education, emphasizing: (1) the improvement of teaching methods in medical teaching institutions, encompassing from the entrance process and teaching-learning evaluation to the study and enhancement of medical education theories and the establishment of effective cooperation and participation with organizations representative of the student body of affiliated entities; (2) development of studies aiming at establishing minimum requirements for accreditation of hospitals that serve the affiliated entities for the purpose of Internship and Medical Residency, in agreement with organizations legally in charge of this task, as well as the entities representative of the interested parties and (3) the enhancement of the technical and administrative organization of medical schools, of public health, as well as hospitals that serve teaching purposes. ${ }^{5}$ The mission of ABEM consists in the development of medical education starting with the "formation of a professional able to meet the health needs of the population" and that will contribute "to the construction of a more just and egalitarian society". ${ }^{5}$

A few years later, when Brazil had 62 courses of medicine, the concern with the rising number of courses generated the creation of the Commission of Medical Teaching (Comissão de Ensino Médico) by the Ministry of Education and Culture (MEC), in 1971, blocking the concession of authorization for the operation of courses of medicine for approximately 13 years. Such decision was taken by the Commission after analysis of questionnaires sent to the medical schools and visiting each one of them. There already was, therefore, a concern with the didactic-pedagogical aspects. ${ }^{6}$

The reformulation of the Brazilian educational system had a new milestone in the Law of National
Education Guidelines and Bases (Lei de Diretrizes e Bases da Educação Nacional - LDB), Law n. 9.394, dated December 20,1996, and the 1990s registered the creation of 17 courses of Medicine, according to data of INEP/MEC. In the same decade, evaluation of courses was instituted as a policy of the New National Education Plan, with the National Course Exam (Provão), according to Law 9.131/95. Years later, the Resolution CNE/CES N ${ }^{\circ}$. 4, dated November 7, 2001, established the National Curriculum Guidelines of the Undergraduate Course of Medicine and, among the competences and abilities required for professional activity foresaw education focused on health care, decision making, communication, leadership, administration, management and continuing education. ${ }^{7}$

The curriculum reforms in Medical Teaching are occurring worldwide and bring to mind reflections about what would be sufficient time dedicated to each area in the formation of the professional as general knowledge, with dermatology inserted in this context. In general, little or no attention is given to the teaching of this specialty during the undergraduate years, in medical residence programs and in family medicine. ${ }^{8}$ However, there are investigations indicating that health professionals, in several locations, do not master the content expected for adequate practice of the profession. ${ }^{9-12}$

The matter of little time assigned to the teaching of Dermatology in courses of Medicine is not only a Brazilian concern. Much has been published regarding teaching the specialty to undergraduate students. ${ }^{13,14,15}$

With the objective of providing the integral development of the required skills, the curricula were altered since the first undergraduate year of the School of Medical Science at the State University of Campinas (Faculdade de Ciências Médicas, Universidade Estadual de Campinas - FCM/UNICAMP). These alterations made an increase in the time devoted to the teaching of Dermatology possible, aiming at a better preparation of the physicians concerning the specialty. Thus, as of the third year in the new curriculum, the students have contact with Clinical Dermatology in the module of Integrated Pathophysiology. In the fourth year, practical activities of observation are developed in the specialty outpatient clinics at the Teaching Hospital, in addition to new theoretical content. In the fifth year of this curriculum, the graduates see patients with dermatoses at a local Basic Health Unit (UBS). ${ }^{10}$

This study assessed the relevance of Dermatology in medical practice of FCM/Unicamp graduates, with the objective of knowing and comparing the vision of these groups of graduates regarding the curriculum of the course and the degree of confidence 
regarding the diagnosis, diagnostic investigation and treatment of patients with dermatoses. Our intention was to learn the vision of non-dermatologist graduates about the relevance of the specialty teaching in the undergraduate curriculum and in professional experience. Considering that medicine course graduates are the most able actors to evaluate the curriculum, in view of its applicability to the professional area, they were requested to point out its positive character or not.

In order to learn the opinion of the graduates, the subjects were divided into two groups (G1 and G2). G1 grouped those graduated for less than ten years and was subdivided into: G1A, with those who graduated between 2006-2008 and G1B, with those who graduated between 2004 and 2005. G2 was composed of those graduated from 1994 to 1998. The new curriculum analysis is represented by G1A, while the old curriculum analysis is represented by G1B.

\section{METHODS}

This is a study with a quantitative and qualitative approach, based on the comparison of two groups of graduates joined according to time elapsed since graduation and one of them subdivided according to the curriculum:

-G1A: graduated for less than 10 years, new curriculum (2006-2008);

-G1B: graduated for less than 10 years, old curriculum (2004-2006);

- G2: graduated for more than 10 years, old curriculum (1994-1998).

The study is characterized as observational of the cross-sectional type, with a descriptive analytical approach. ${ }^{16-19}$

The sample was composed of 126 graduates of the course of Medicine of FCM/Unicamp. At first, our intention was to obtain the electronic addresses of physicians from the Regional Council of Medicine of the State of São Paulo; however, as that entity refused our request, the research was sent to 143 addresses obtained by means of the social network or from school records. In this study, the non-probability convenience sampling with sequential allocation of cases was used. ${ }^{20}$

The investigation was authorized by the Research Ethics Committee of the school. Participation was voluntary and the objectives of the study were explained in the term of informed consent that accompanied the electronic questionnaire.

A preliminary test was carried out with 10 physicians graduated in other years from the FCM/Unicamp, observing the time required for the answers and discussing the interpretation of the answers so as to obtain the final version of the instrument for electronic mailing.

The structured questionnaire had 22 closed and 2 open questions.

Data were collected in real time by means of the investigation program Encuestafacil in the period from February to October 2011 and stored online, generating a spreadsheet with all the answers and its transference to the program Statistical Package for Social Sciences (SPSS), version 15, processed as tables with the relative and absolute frequencies. ${ }^{16,21}$ In order to compare proportions were used the chi-square test, Fisher exact test for tables $2 \times 2$ and Fisher-Freeman-Halton exact test for the larger tables. In every case the 5\% significance level was adopted.

The questions were dichotomically addressed by multiple choice. The data obtained were expressed as percentages for each group of graduates.

The first open question sought to know the reasons for the relevance of dermatological knowledge in medical practice, and the second, which were the most important contributions acquired in the undergraduate course about Dermatology. The answers were analyzed according to the Content Analysis of Bardin, aided by the program Nvivo $10 .{ }^{17,18}$

\section{RESULTS}

The study counted with the participation of 131 respondents, but five of them informed they were specialized in dermatology and for that reason did not integrate the analysis; therefore, the samples of 126 respondents were considered valid. There were respondents of both genders ( $57.1 \%$ female); $47.6 \%$ were in the 27 to 30 -year-old age group; $83.3 \%$ had completed specialization courses in other areas.

The respondents were divided into groups, as follows: 33.3\% for the period between 2006 and 2008 (G1A); 31.7\% for the period between 2004 and 2005 (G1B); and 34.9\% for the period between 1994 and 1998 (G2).

As regards a training period after graduation, $9.6 \%$ informed it was part of the residency program or medical specialization: 7.1\% (G1A), $14.6 \%$ (G1B) and $7.1 \%$ (G2). Concerning the length of the training period, $8 \%$ had a training period of only one month.

The remaining results at first show all groups together and then highlight the data obtained when the groups are compared.

The graduates were requested to inform if they worked for the public or private sector and the respective place of work. It was found that among those who informed that they worked for the private sector, $40.5 \%$ worked at offices and hospitals, $50.8 \%$ at hospitals, while $28.6 \%$ worked at clinics. As for those who worked for the public sector: $27 \%$ worked at health 
centers/specialized facilities and $73 \%$ at hospitals.

It was observed that among those who informed as area of professional activity Internal Medicine, the prevalent specialties were: Cardiology (14.3\%) and Infectious Diseases (10.7\%). Among those who informed the area of Surgery, the outstanding ones are: General and Trauma (22.2\%), Plastic (16.7\%), Thoracic (11.1\%) and Gastrosurgical (11.1\%).

The study had the aim of identifying the age group of the patients cared for and the question admitted multiple choices; thus it was found that the largest percentage of patients was in the adult group (73\%), while the pediatric and geriatric segments had similar percentages, with $46.8 \%$ and $42.1 \%$ respectively. The investigation also aimed to know the weekly average of appointments. Among the respondents, $41.2 \%$ saw between 51 and 100 patients per week, while 36\% saw up to 50 patients.

It was found that $35 \%$ of participants informed they saw between 5 and $10 \%$ of patients who presented dermatoses that required further assessment and $20.5 \%$ informed they saw between 10 and $25 \%$ of patients in the same condition.

Still focusing patient care, it was inquired what was the percentage of dermatoses that comprised the main reason for the appointment and, in this topic, the results were the following: $35 \%$ informed that less than $5 \%$ of patients looked for specific care, $22.2 \%$ informed that 5 to $10 \%$ of the patients listed dermatoses as the main reason for the appointment, while $6 \%$ of respondents reported that 10 to $25 \%$ of appointments corresponded to dermatoses.

Based on the information obtained, it became of interest to learn the relevance of dermatological knowledge in medical practice. Considering all graduates, the answers were distributed as: high (51.3\%), medium $(25.6 \%)$ and low $(23.1 \%)$.

The percentage of patients requiring evaluation was compared with the variable of knowledge acquired in the specialty during the undergraduate course. Of the 117 non-dermatologist physicians who answered the question, 65 affirmed that the knowledge acquired about Dermatology was sufficient, in the following proportions: $52.8 \%$ of the physicians who saw less than $5 \%$ of patients with dermatoses; $65 \%$ of the physicians who saw between 5 and $10 \%$; $50 \%$ of those who saw between 10 and $25 \%$; $60 \%$ of those who saw between 25 and $50 \%$; and $75 \%$ of the physicians who saw more than $50 \%$ of patients with dermatoses (Graph 1).

The three groups (G1A, G1B and G2) were distributed so as to generate 2 main groups, one for curriculum [G1A X G1B] and another for time elapsed since graduation [(G1A + G1B) X G2], as the interest was in assessing the degree of confidence regarding

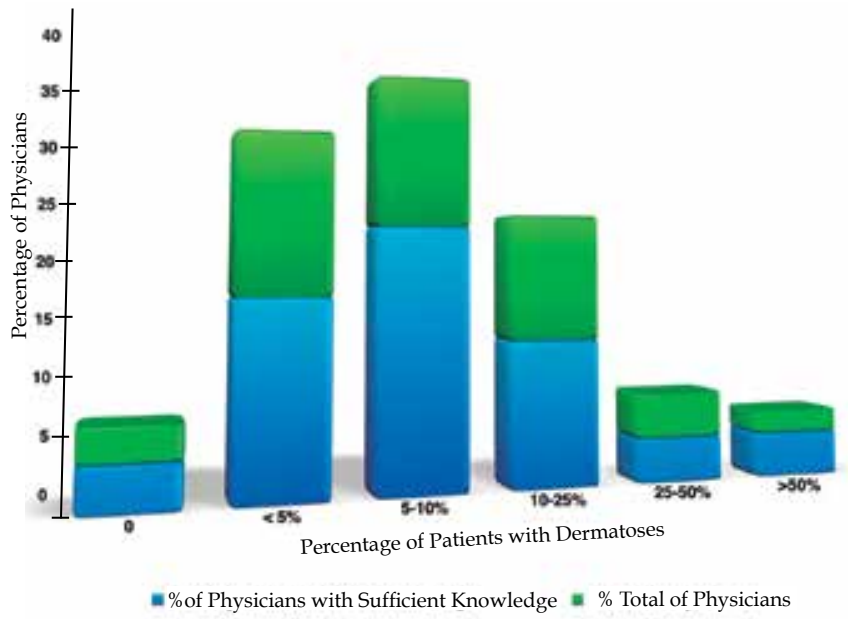

GRAPH 1: Dermatosis (requiring evaluation) versus dermatological knowledge

the diagnosis, diagnostic investigation and treatment of patients with dermatoses, as well as the relevance of dermatological knowledge in medical practice among the groups.

As to the curriculum, graduates for less than 10 years both by the new curriculum and by the old one did not present statistically different opinions regarding confidence (Table 1). Only a minority felt very confident to treat patients with dermatoses.

Concerning the time elapsed since graduation the students who were graduated for less than 10 years mentioned feeling more confident in relation to the diagnosis, the diagnostic investigation and treatment of dermatoses when compared to those who were graduated for more time. Most of the graduated for more than 10 years (G2) mentioned feeling insecure in face of patients with dermatoses regarding the diagnosis of the lesions $(48.7 \%)$, the diagnostic investigation $(64.8 \%)$ and treatment of dermatoses $(72.9 \%)$ (Table 2).

There was no statistical difference between the confidence of students graduated for less than 10 years by the different curricula (G1A X G1B), even though less insecurity was observed in those graduated by the new curriculum, particularly in relation to the diagnostic investigation and treatment of dermatoses.

In relation to the relevance of dermatological knowledge in medical practice there was statistical difference only regarding the time elapsed since graduation: those graduated for less than 10 years valued knowledge about the specialty more ( $\mathrm{p}$-value $=0.008$ ). Only a minority in all of the groups considered the relevance of the specialty low (Table 2).

In addition to closed questions, the graduates answered two open questions. Each of them consisted in a category: Medical Practice and Contributions of Graduation. 
TABLE 1: Degree of confidence and relevance of knowledge according to curriculum

\begin{tabular}{llll}
\hline CURRICULUM & G1A & G1B & p-value \\
& $n(\%)$ & $n(\%)$ &
\end{tabular}

What is your degree of confidence when

0.892 diagnosing a lesion?

$\begin{array}{lll}\text { Low } & 9(22.5) & 10(25.6) \\ \text { Medium } & 22(55.0) & 18(46.2) \\ \text { High } & 9(22.5) & 11(28.2)\end{array}$

What is your degree of confidence

0.164

in diagnostic investigation, when required?

$\begin{array}{lll}\text { Low } & 8(200) & 13(33.4) \\ \text { Medium } & 18(45.0) & 15(38.5) \\ \text { High } & 14(35.0) & 11(28.2)\end{array}$

What is your degree of confidence in the treatment? 0.371

$\begin{array}{lll}\text { Low } & 12(30.0) & 17(43.6) \\ \text { Medium } & 20(50.0) & 15(38.5) \\ \text { High } & 8(20.0) & 7(17.9)\end{array}$

What is the relevance of dermatological

0.508

knowledge in your medical practice?

\begin{tabular}{lll} 
Low & $4(9.0)$ & $7(18.0)$ \\
Medium & $9(22.5)$ & $13(33.3)$ \\
High & $27(67.5)$ & $19(48.7)$ \\
\hline
\end{tabular}

G1A: Graduated for less than 10 years, new curriculum.

G1B: Graduated for less than 10 years, old curriculum. G2: Graduated for more than 10 years, old curriculum.

*One graduate (G1A) and one from the (G1B + G2) group considered the dermatological knowledge irrelevant in medical practice.

The data were analyzed by means of successive readings of the answers so that subcategories were identified and quantified. ${ }^{3,4}$ Tables 3 and 4 present these categories and their subcategories.

The most frequently found subcategories in Medical Practice (Table 3) were: Dermatology, Dermatoses, Diagnosis, Specialty, Lesions and Patients. Graduates by the old curriculum (G1B and G2) emphasized the subcategories: lesions (39\%); patients $(27 \%)$; dermatosis $(20 \%)$, dermatology (19\%) and diagnosis (19\%), while those graduated by the new curriculum (G1A) emphasized: dermatosis $(27 \%)$, diagnosis $(21 \%)$ and patients $(21 \%)$. The six subcategories were found both in those who graduated by the new curriculum and those who graduated by the previous curriculum, as seen in excerpts of statements of graduates (Table 3):

"Being a pediatrician, dermatology is very important due to the great incidence of cases. It is not larger in my case because I work only in ICU and the dermatological diagnosis ends up being secondary in most cases."
TABLE 2: Degree of confidence and relevance of knowledge according to time since graduation

\begin{tabular}{llll}
\hline TIME SINCE & G1A + G1B & G2 & p-value \\
GRADUATION & $\mathbf{n}(\%)$ & $\mathbf{n}(\%)$ &
\end{tabular}

$\begin{aligned} & \text { What is your degree of confidence } \\ & \text { when diagnosing a lesion? }\end{aligned}$
$\begin{array}{lll}\text { Low } & 19(23.8) & 18(48.7) \\ \text { Medium } & 41(51.3) & 16(43.2) \\ \text { High } & 20(35.2) & 3(8.1)\end{array}$

0.026

What is your degree of confidence in 0.000 diagnostic investigation, when required?
Low
$21(26.3) \quad 24(64.8)$
Medium
$34(42.4) \quad 10(27.0)$
High
$25(31.3) \quad 3(8.1)$

What is your degree of confidence in

0.003 the treatment?

$\begin{array}{lll}\text { Low } & 29(36.2) & 27(72.9) \\ \text { Medium } & 36(45.0) & 9(24.3) \\ \text { High } & 15(18.8) & 1(2.7)\end{array}$

What is the relevance of dermatological

knowledge in your medical practice?

$\begin{array}{lll}\text { Low } & 11(13.8)^{*} & 16(43.2)^{*} \\ \text { Medium } & 22(27.5) & 8(21.6) \\ \text { High } & 47(58.7) & 13(35.2)\end{array}$

G1A: Graduated for less than 10 years, new curriculum. G1B: Graduated for less than 10 years, old curriculum. G2: Graduated for more than 10 years, old curriculum. *One graduate (G1A) and one from the (G1B + G2) group considered the dermatological knowledge irrelevant in medical practice.

TABle 3: Category I - Medical Practice

\begin{tabular}{llll}
\hline & $\begin{array}{l}\text { G1A } \\
\mathbf{n}(\mathbf{\%})\end{array}$ & $\begin{array}{l}\text { G1B } \\
\mathbf{n}(\mathbf{0})\end{array}$ & $\begin{array}{l}\text { G2 } \\
\mathbf{n}(\mathbf{\%})\end{array}$ \\
\hline Dermatology & $1(4)$ & $3(10)$ & $5(19)$ \\
Dermatosis & $9(27)$ & $6(20)$ & $4(15)$ \\
Diagnosis & $7(21)$ & $4(13)$ & $5(19)$ \\
Specialty & $6(18)$ & $1(3)$ & $1(4)$ \\
Lesions & $3(9)$ & $12(39)$ & $4(15)$ \\
Patients & $7(21)$ & $5(15)$ & $7(27)$ \\
\hline
\end{tabular}

G1A: Graduated for less than 10 years, new curriculum. G1B: Graduated for less than 10 years, old curriculum. G2: Graduated for more than 10 years, old curriculum. 
TABLE 4: Category II - Contributions of Graduation

\begin{tabular}{llll}
\hline & G1A & G1B & G2 \\
& $\mathbf{n}(\%)$ & $\mathbf{n}(\%)$ & $\mathbf{n}(\%)$ \\
\hline Outpatient care & $2(8)$ & $1(6)$ & $1(12.5)$ \\
Ability to diagnose & $4(15)$ & $1(6)$ & $2(25)$ \\
Knowledge of pathology & $3(12)$ & $1(6)$ & $4(50)$ \\
Investigation of dermatosis & $1(4)$ & $2(12)$ & $0(0)$ \\
Recognition of lesions & $16(61)$ & $12(70)$ & $1(12.5)$ \\
\hline
\end{tabular}

G1A: Graduated for less than 10 years, new curriculum. G1B: Graduated for less than 10 years, old curriculum. G2: Graduated for more than 10 years, old curriculum.

"I am a plastic surgeon and the intersection with dermatology is permanent in my clinical practice, mainly regarding cutaneous neoplasms."

"An appropriate differential diagnosis is very important and makes a difference for the patient."

"I believe that I can identify some dermatological diseases, mainly those that require referral for specialized treatment by a dermatologist, and also to include them in the investigation and clinical picture of endocrine pathologies, but as a rule I identify them and refer the patient to the dermatologist for treatment."

"As systemic diseases may present through skin lesions, it is necessary to recognize them and know how to make differential diagnosis."

"Several pathologies in internal medicine and hematology present cutaneous manifestations, which oftentimes are the first sign that motivates the patient to look for health services. They are also manifestations that cause discomfort and concern to the patients, who demand a safe and efficient conduct from the health professional."

In the category Contributions of graduation five subcategories were identified, more prevalent in the speech of the investigated groups, pictured in table 4 .

The most incident subcategories in the category Contributions of graduation (Table 4) were: Outpatient care, Ability to diagnose, Knowledge of pathology, Investigation of dermatosis and Recognition of lesions. It was found that those graduated by the old curriculum (G1B and G2) emphasized the subcategories: Recognition of lesions (70\%); Knowledge of pathology (50\%); Ability to diagnose (25\%), Investigation of dermatosis (12\%); while those graduated by the new curriculum (G1A) emphasized: recognition of lesions (61\%) and ability to diagnose (15\%). The five subcategories were found in the groups, as seen in excerpts of statements made by graduates (Table 4 ): ical diseases."
"The correct diagnosis, when related to the diseases of my specialty, enabled me to treat a few diseases."

"Recognition of elementary lesions. Characterization of syndromes (eczematous, tumoral, bullous...). Treatment of more prevalent dermatoses."

"All practical care during internship in dermatology, outpatient clinic and in wards, learning about chronic dermatological diseases (ex: psoriasis, squamous cell carcinoma) and rare diseases (Sézary syndrome)."

"Differential diagnosis, to recognize the pathologies, to know when to refer and when to investigate systemic disease (and not treat it but wait for the dermatologist)."

"I had contact with the most common dermatological pathologies and feel confident to treat them. I can also describe well the elementary lesions and look for the diagnosis or refer at a more advanced phase of the investigation, when possible."

\section{DISCUSSION}

Dermatological complaints are frequent at Basic Health Units (UBS). An investigation carried out at Unicamp showed that one in every ten users seen at UBS looked for treatment for a dermatosis and one in every five had a dermatosis as complaint or exam finding. ${ }^{10}$ This study showed that most (55.6\%) of FCM/Unicamp non-dermatologist graduates see up to between 5 and $25 \%$ of patients with dermatoses (Graph 1 ).

One in every five graduates of several specialties $(21.2 \%)$ affirmed that 5 to $10 \%$ of patients were seeking care for a dermatosis. For $51.3 \%$ of the graduates the relevance of dermatological knowledge is high, and when asked about the reasons for this relevance the graduates mentioned the importance of recognizing the lesions and making the correct diagnosis, mainly for the great number of children and pregnant women assisted.

The data showed that the discipline of Dermatology is relevant in medical practice and that FCM/ Unicamp physicians graduated for less than 10 years feel more confident facing a patient with dermatosis when compared to doctors who graduated more than 10 years ago. As to the opinion of non-dermatologist graduates regarding the relevance of the specialty in their medical practice, it was observed that physicians graduated by both curricula, as well as those graduated for more or for less than 10 years that consider the relevance of the specialty low are a minority.

It should be emphasized that the graduates worked both at public and private health services and that more than $80 \%$ of them had completed residency and acted in different specialties. Most of the physicians who graduated from the FCM/Unicamp and 
participated in the study worked with adult patients, but a great part of them worked also with children $(46.8 \%)$ and elderly patients $(42.1 \%)$. Three in every four graduates examined up to 100 patients per week.

When all respondents were considered, the relevance of the specialty was judged high by more than $40 \%$ and medium by around $25 \%$ of them. The knowledge acquired in undergraduate school was considered sufficient by most of the graduates.

In the comparative analysis of groups it became evident that the longer time elapsed since graduation brought more insecurity to graduates regarding diagnosis, diagnostic investigation and treatment. When the different curricula completed by those graduated for less than ten years were compared, it was not possible to detect a statistically significant difference, maybe due to the number of respondents, although students who were graduated by the new curriculum showed a tendency to feel more confident, particularly regarding diagnostic investigation and treatment (Table 2).

It is noteworthy that those who were graduated for more than ten years admitted greater insecurity when facing patients with dermatoses, but gave less relevance to the specialty in their medical practice. This may suggest that the better prepared the physician is in his specialty, the more valued will it be in his professional experience.

\section{CONCLUSION}

The open questions allowed us to conclude that, independently from the curriculum, the graduates prioritize dermatoses, the diagnosis, the specialty, the lesions and the patients in their medical practice; as to the contributions of graduation, they value outpatient care, the ability to diagnose, knowledge of pathology, investigation of the dermatosis and the recognition of lesions.

The little time dedicated to the teaching of Dermatology in some undergraduate courses of Medicine should be reviewed, considering the high prevalence of dermatological complaints in medical practice.

It may be concluded that Dermatology is relevant in the clinical practice of most graduates from FCM/ Unicamp and that those graduated more recently feel less insecure when facing a patient with dermatosis.]

\section{REFERENCES}

1. Anjos Neto MR, Moura Al. Construção e teste de um modelo teórico de marketing de relacionamento para 0 setor de educação. CD-ROM. Anais do Encontro da ANPAD. Curitiba; 28; 2004.

2. Meira MDD, Kurcgant P. Avaliação de curso de graduação segundo egressos. Rev Esc Enferm USP. 2009;43:481-5.

3. Walter AS, Tontini G, Domingues MJCS. Análise da satisfação do aluno para melhoria de um curso de Administração. FACES Adm. 2006;6:52-70.

4. Richardson RJ. Pesquisa Social: Métodos e Técnicas. São Paulo: Atlas; 2007.

5. Abem-educmed.org [Internet]. Associação Brasileira de Educação Médica (ABEM). 0 que é a ABEM? [acesso 22 Mar 2013]. Disponível em: http://www. abem-educmed.org.br/sobre_abem.php. Acesso em: 30/10/2014.

6. Briani MC. História e Construção social do currículo na educação médica: a trajetória do curso de medicina da Faculdade de Ciências Médicas da UNICAMP [dissertação]. Unicamp (SP): Universidade Estadual de Campinas; 2003.

7. Conselho Nacional de Educação. Câmara de Educação Superior. Resolução CNE/ CES 4/2001. Institui Diretrizes Curriculares Nacionais do Curso de Graduação em Medicina. Diário Oficial da União 7 nov de 2001.

8. Kirsner RS, Federman DG. Lack of Correlation between Internists' Ability in Dermatology and Their Patterns of Treating Patients with Skin Disease. Arch Dermatol. 1996;132:1043-6.

9. Santos Jr A, Andrade MGG, Zeferino AMB, Passeri SMRR, Souza, EM, Velho PENF. Evaluación de conocimientos médicos: diagnóstico de afecciones dermatológicas prevalentes. Educ Med. 2010;13:47-52.

10. Santos Jr A, Andrade MGG, Magalhães RF, Moraes AM, Velho PENF. Prevalence of dermatoses in the primary health care system of Campinas, São Paulo - Brazil. An Bras Dermatol. 2007;82:419-24.

11. Whitaker-worth DL, Susser WC, Grant-kels JM. Clinical dermatologic education and the diagnostic acumen of medical students and primary care residents. Int $\mathrm{J}$ Dermatol. 1998;37:855-9.

12. Stephenson A, From L, Cohen A, Tipping J. Family physicians' knowledge of malignant melanoma. J Am Acad Dermatol. 1997;37:953-7.

13. Chiang YZ1, Tan KT, Chiang YN, Burge SM, Griffiths CE, Verbov JL. Evaluation of educational methods in dermatology and confidence levels: a national survey of UK medical students. Int Int J Dermatol. 2011;50:198-202.

14. Hajjaj FM, Salek MS, Basra MK, Finlay AY. Non clinical influences, beyond diagnosis and severity, on clinical decision making in dermatology: understanding the gap between guidelines and practice. Br J Dermatol. 2010;163:789-99.

15. Kaliyadan F. Undergraduate dermatology teaching in India: need for change. Indian J Dermatol Venereol Leprol. 2010;76:455-7.

16. Norusis MJ. SPSS Professional Statistics 15. Chicago: SPSS; 2003.

17. Amaral IS. Curso Completo NVivo 10. E-book. Portugal: Bubok; 2012.

18. Bardin L. Análise de Conteúdo. Lisboa: Edições 70; 1991.

19. Oliveira G, Oliveira E, Leles C. Tipos de delineamento de pesquisa de estudos publicados em periódicos odontológicos brasileiros. Rev Odonto Ciência, 2007;22:42-7.

20. Babbie, E. The Pratice of Social Research. 9th ed. Belmont, CA: Wadsworth; 2001.

21. Encuestafacil.com.br [Internet]. Ferramenta web de pesquisas online. [acesso 30 out 2014]. Disponível em: http://www.encuestafacil.com/
MAILING ADDRESS:
Paulo Eduardo Neves Ferreira Velho
Universidade Estadual de Campinas
Faculdade de Ciências Médicas
R. Tessália Vieira de Camargo, 126
Cidade Universitária "Zeferino Vaz"
13083-887 - Campinas - SP
Brazil
E-mail:pvelho@unicamp.br

How to cite this article: Lugão AF, Caldas TA, Castro EL, Pereira EMA, Velho PENF. Dermatology relevance to graduates from the Universidade Estadual de Campinas Medical School. An Bras Dermatol. 2015;90(5):631-7. 